\title{
Editorial
}

\section{Pensando la cultura en tiempos de globalización}

En los últimos años, la dimensión cultural de la realidad nacional viene recibiendo un creciente interés por parte de los investigadores. Ante los decepcionantes resultados del proceso de transición democrática de la última década, la pregunta se vuelve cada vez más hacia las condicionantes subjetivas que entran en juego en el arduo proceso de construir una sociedad más justa y solidaria. En la cultura, pues, se vuelve importante prestar atención a aquellos aspectos que configuran la subjetividad, la sensibilidad y la emotividad de las personas y los grupos que componen la realidad del país.

Desde esta perspectiva, es importante notar los cambios radicales que la sociedad salvadoreña ha experimentado en las últimas décadas y el impacto que estos cambios tienen en la conformación de sujetos sociales. En primer lugar, habria que notar que si nuestra mitologia nacional nos entrega siempre una imagen pastoril, de un El Salvador agrario y campesino, la realidad es muy otra. No sólo la urbanización de nuestro país es visible por un cambio en la naturaleza de las actividades económicas o por el desplazamiento de la población del campo hacia las ciudades. Más dramáticas sean, quizás, la contracción e implosión de las culturas campesinas del país, 
con la pérdida de autoridad y de viabilidad de una serie de saberes sobre el mundo y sobre las relaciones del mundo que ello conlleva. La pérdida de sustento de estos saberes y el desprestigio total de quienes los detentan tradicionalmente explique, tal vez en parte, muchos procesos de anomia $y$ de desintegración social que son más que alarmantes.

Otro cambio importante es la transnacionalización de la sociedad salvadoreña. La migración masiva de salvadoreños no sólo ha representado el desplazamiento fisico de millones de compatriotas, sino un cambio radical en la definición del espacio geográfico con consecuencias insospechadas en la definición de la ciudadanía, el Estado y hasta la familia y las mismas nociones de identidad personal.

Finalmente, los salvadoreños no son ajenos a los impactos de los cambios más de fondo del sistema mundial, donde la lógica mercantil ha terminado por determinar y definir lo social y lo cultural. La expansión y redefinición global de las industrias culturales han cambiado totalmente los espacios de referencia y las identidades.

Esos cambios plantean desafios enormes a cualquier aspiración de cambio en dirección en búsqueda de relaciones sociales más humanas y justas. Toda aspiración de cambio social debe asumir esos retos para que sus planteamientos sean viables y capaces de conectarse con los sentires $y$ aspiraciones de las personas, especialmente de aquellas más ávidas y necesitadas de justicia.

Pensar la nación, como aspiración de sociedad más justa y con poder de autodeterminación, supone varias cosas. En primer lugar, El Salvador debe tomar distancia a las fantasías de homogeneidad de los discursos nacionalistas hegemónicos y asumirse como una sociedad diversa, social y culturalmente. Esto puede parecer contradictorio, por tratarse de un país tan pequeño en extensión territorial y población, pero es una realidad contundente, que la urbanización y transnacionalización agudizan todavia más. Hay un país indigena, un país urbano, un país rural y un pais "salvadoran" o "salvatrucho". Tal vez el gran trabajo de una política cultural es transformar esa multitud de experiencias en un verdadero sueño común, que parte del reconocimiento de todos. 
Consecuentemente, el otro reto es pensar la nación, no como una esencia orgánica, sino como un lugar de encuentro y diálogo entre las distintas comunidades salvadoreñas, buscando atender de manera especial a aquellas tradicionalmente marginadas y a las dispersas por los movimientos migratorios.

Este trabajo entraña, finalmente, una parte práctica. La cultura no sólo es un conjunto de ideas y simbolos. También supone una infraestructura real, de espacios de encuentro, redes de intercambio, canales de difusión y agentes de producción. Ello conlleva explorar y repensar a fondo las industrias culturales, $y$ sobre todo, tratar de transgredir la brecha sólo aparentemente infranqueable entre lo culto y lo mediático, entre lo artístico y el entretenimiento. Sólo así, las aspiraciones podrán pasar del terreno de las intenciones al de las acciones concretas 